\title{
Original
}

\section{Inhibitory effects of trichostatin A on adrenocorticotropic hormone production and proliferation of corticotroph tumor AtT-20 cells}

\author{
Yuki Nakada ${ }^{1)}$, Kazunori Kageyama ${ }^{1), 2)}$, Aya Sugiyama ${ }^{1)}$, Rie Desaki ${ }^{1)}$, Shinobu Takayasu' ${ }^{1), 2)}$, \\ Kanako Niioka $^{1)}$, Shingo Murasawa ${ }^{1)}$, Noriko Ishigame ${ }^{1)}$, Yuko Asari ${ }^{1)}$, Yasumasa Iwasaki ${ }^{3)}$ and \\ Makoto Daimon ${ }^{1)}$ \\ 1) Department of Endocrinology and Metabolism, Hirosaki University Graduate School of Medicine, Aomori 036-8562, Japan \\ 2) Department of Endocrinology, Metabolism, and Infectious Diseases, Hirosaki University School of Medicine \& Hospital, \\ Aomori 036-8563, Japan \\ 3) Health Care Center, Kochi University, Kochi 780-8520, Japan
}

\begin{abstract}
Cushing's disease is primarily caused by adrenocorticotropic hormone (ACTH)-producing pituitary adenomas. Pituitary tumor-transforming gene 1 ( $P T T G 1)$ expression, a hallmark of pituitary tumors, stimulates pituitary cell proliferation. Histone deacetylases (HDACs) play an important role in regulating gene transcription and HDAC inhibitors induce cellular differentiation and suppress tumor cell proliferation. HDAC inhibitors also repress PTTG1 mRNA levels. Trichostatin A (TSA) is a potent cell-permeable HDAC inhibitor that blocks cell cycle progression. In the present study, we determined the effect of TSA on ACTH production and cellular proliferation in mouse AtT-20 corticotroph tumor cells. TSA decreased proopiomelanocortin $(P O M C)$ mRNA levels in AtT-20 cells and reduced ACTH levels in the culture medium of these cells. The TSA-induced decreases in POMC mRNA levels were not modulated when TSA and dexamethasone were simultaneously administered. Drug treatment also decreased AtT-20 cell proliferation, induced apoptosis, and increased the percentage of cells in G0/G1 phase using flow cytometry. TSA decreased PTTG1 mRNA levels. Furthermore, $P T T G 1$ knockdown inhibited cellular proliferation. Its knockdown also inhibited POMC mRNA and ACTH levels. TSA inhibits ACTH production and corticotroph tumor cell proliferation. TSA may inhibit cellular proliferation, and ACTH synthesis and secretion by decreasing PTTG1 expression.
\end{abstract}

Key words: Cushing's disease, Adrenocorticotropic hormone (ACTH), Proopiomelanocortin (POMC), Pituitary tumor, Trichostatin

CUSHING'S DISEASE is primarily caused by adrenocorticotropic hormone (ACTH)-producing pituitary adenomas $[1,2]$. In adenoma cells, the normal cortisol feedback mechanism of the hypothalamic-pituitary-adrenal axis is disturbed, resulting in hypercortisolism which results in metabolic derangements such as diabetes mellitus, hypertension, atherosclerosis, and immune dysfunction [3]. ACTH production may be associated with cell mass or pituitary corticotroph tumor cell growth [4]. Tumor growth is determined, at least in part, by cellular proliferation, cell cycle pro-

Submitted Jun. 29, 2015; Accepted Sep. 16, 2015 as EJ15-0369 Released online in J-STAGE as advance publication Oct. 23, 2015 Correspondence to: Kazunori Kageyama, M.D., Ph.D., Department of Endocrinology and Metabolism, Hirosaki University Graduate School of Medicine, 5 Zaifu-cho, Hirosaki, Aomori 036-8562, Japan. E-mail: kkageyama@hkg.odn.ne.jp gression, and apoptosis [5].

Pituitary tumor-transforming gene 1 (PTTG1) is an oncogene that was first cloned from a rat pituitary tumor [6]. PTTG1 expression is a hallmark of pituitary tumors $[7,8]$. PTTG facilitates cell cycle progression, increases pituitary cell proliferation, and promotes murine pituitary development [9]. Heat shock protein 90 (Hsp90) is an essential molecular chaperone involved in the folding and stabilization of client proteins which regulate the survival of cancer cells. Hsp90 inhibitors have been reported to repress PTTG1 expression in carcinoma cells $[10,11]$, and are thought to act in a similar way in pituitary tumor cells. Previous studies have demonstrated that Hsp90 inhibitors decreased POMC mRNA and ACTH levels in AtT20 cells $[12,13]$. These drugs have also been shown to decrease PTTG1 mRNA and cellular proliferation in 
AtT-20 cells. The modification of histone acetylation plays an important role in controlling PTTG1 expression. Histone deacetylase (HDAC) inhibitors suppress PTTG1 mRNA levels in a manner similar to Hsp90 inhibitors [11].

Of the numerous HDACs have been identified, the prototypical ones are HDACs 1, 2, and 3. HDACs play an important role in regulating gene transcription. HDAC inhibitors induce cellular differentiation and suppress tumor cell proliferation [14]. Trichostatin A (TSA), originally used as an antifungal drug, is a representative hydroxamic acid-based natural product that possesses an HDAC inhibitor activity. TSA is a potent, cell-permeable HDAC1 and 2 inhibitor which blocks cell cycle progression.

In the present study, we examined the effect of TSA on ACTH production and cellular proliferation in AtT20 corticotroph tumor cells. To further elucidate the possible mechanisms of TSA action, we also examined the effect of PTTG1 on cellular proliferation.

\section{Materials and Methods}

\section{Materials}

TSA was purchased from Calbiochem (San Diego, CA, USA), dissolved in dimethyl sulfoxide (DMSO), diluted with cell culture medium, and used at concentrations between $10 \mathrm{nM}$ and $10 \mu \mathrm{M}$.

\section{Cell culture}

AtT-20 pituitary corticotroph tumor cells were cultured in $\mathrm{T}_{75}$ culture flasks with Dulbecco's modified Eagle's medium (DMEM) supplemented with 10\% fetal bovine serum (FBS), $100 \mu \mathrm{g} / \mathrm{mL}$ streptomycin, and $100 \mathrm{U} / \mathrm{mL}$ penicillin at $37^{\circ} \mathrm{C}$ in a humidified atmosphere of $5 \% \mathrm{CO}_{2}$. The cells were seeded in 6-well plates at a density of $1.5 \times 10^{5}$ cells/well and grown for 3 days before each experiment. The culture medium was changed every $48 \mathrm{~h}$. To minimize the effect of exogenous factors contained within FBS, one day before each experiment, cells were washed and serum starved overnight with DMEM supplemented with $0.2 \%$ bovine serum albumin. At the end of each experiment, total cellular RNA or protein was collected and stored at $-80^{\circ} \mathrm{C}$ until the relevant assay was performed.

\section{RNA extraction}

Cells were incubated with medium alone (control) or medium containing TSA for the indicated times. To examine the dose-dependent effects of TSA, cells were incubated for the indicated times with medium alone (control) or medium containing increasing concentrations of TSA (100 nM to $10 \mu \mathrm{M})$. At the end of each experiment, total cellular RNA was extracted using the RNeasy Mini Kit (QIAGEN, Hilden, Germany) in accordance with the manufacturer's protocol. Complementary DNA (cDNA) was synthesized from $0.5 \mu \mathrm{g}$ of total RNA with random hexamer primers using the SuperScript First-Strand Synthesis System for Reverse Transcriptase-Polymerase Chain Reaction (RT-PCR; Invitrogen Corp., Carlsbad, CA) in accordance with the manufacturer's instructions.

\section{Quantitative real-time RT-PCR}

Total cellular RNA extraction and cDNA synthesis were performed as previously described $[15,16]$. The resulting cDNA was subjected to real-time PCR as described below. The expression of mouse POMC (NM_008895.3) and PTTG1 (NM_001131054.1) mRNA were evaluated using quantitative real-time PCR with specific primer and probe sets (Assays-on-Demand Gene Expression Products; Applied Biosystems, Foster City, CA). 32 -microglobulin (B2MG) was used as a reference gene to standardize expression levels. $B 2 M G$ mRNA levels were not significantly altered by any of the treatments used in this study. Each real-time PCR reaction consisted of $1 \times$ TaqMan Universal PCR Master Mix (Applied Biosystems), $1 \times$ Assays-onDemand Gene Expression Products (Mm00435874_m1 for mouse POMC, Mm00479224_m1 for mouse PTTG1, $\mathrm{Mm} 00435121 \mathrm{~g} 1$ for mouse stress response gene growth arrest and DNA damage-inducible $45 \beta$ (GADD45 $\beta$ ), and Mm00437762_m1 for mouse $B 2 M G$ ), and $500 \mathrm{ng}$ of cDNA in a total volume of $25 \mu \mathrm{L}$. Amplification was performed on an ABI PRISM 7000 Sequence Detection System (Applied Biosystems) using the following cycle parameters: $95^{\circ} \mathrm{C}$ for $10 \mathrm{~min}$ followed by 40 cycles of $95^{\circ} \mathrm{C}$ for $15 \mathrm{~s}$ and $60^{\circ} \mathrm{C}$ for $1 \mathrm{~min}$.

Specific sets of primers and a TaqMan probe spanning the exon-exon junction were used in the real-time PCR assays and the results should not, therefore, have been affected by DNA contamination. Data were collected and recorded using the ABI PRISM 7000 SDS software (Applied Biosystems) and are expressed as a function of the threshold cycle $\left(\mathrm{C}_{\mathrm{T}}\right)$. The amplification efficiency of each gene of interest and the reference gene were found to be identical when analyzed using diluted samples.

Relative quantitation of gene expression was calcu- 
lated using the $2^{-\Delta \Delta \mathrm{C}_{\mathrm{T}}}$ method. In brief, for each sample assayed, the $\mathrm{C}_{\mathrm{T}}$ values for the gene of interest and reference gene were determined. The $\mathrm{C}_{\mathrm{T}}$ of the gene of interest was then corrected by subtracting the $\mathrm{C}_{\mathrm{T}}$ of the housekeeping gene $\left(\Delta \mathrm{C}_{\mathrm{T}}\right)$ for each sample. Untreated control samples were used as reference samples, and the $\Delta \mathrm{C}_{\mathrm{T}}$ of all experimental samples was reduced by the average $\Delta \mathrm{C}_{\mathrm{T}}$ of the control samples $\left(\Delta \Delta \mathrm{C}_{\mathrm{T}}\right)$. Finally, the abundance of the experimental mRNA relative to the control mRNA was calculated using the formula $2^{-\Delta \Delta C_{T}}$.

\section{ACTH assay}

Cells were incubated at $37^{\circ} \mathrm{C}$ for $24 \mathrm{~h}$ with the indicated concentrations of TSA. The media was then aspirated and the ACTH level in the supernatants was measured using an ACTH enzyme-linked immunosorbent assay (ELISA) kit (MD Bioproducts, Zurich, Switzerland). The intra- and inter-assay coefficients of variation $(\mathrm{CV})$ were $6.7 \%$ at $42.2 \mathrm{pg} / \mathrm{mL}$ and $7.1 \%$ at $42.3 \mathrm{pg} / \mathrm{mL}$ ACTH, respectively. Cross-reactivity with ACTH fragment (1-24), ACTH fragment (18-39), and $\alpha$-melanocyte-stimulating hormone was $-3.4 \%$, $-2.4 \%$, and $-1.7 \%$, respectively.

\section{Cellular proliferation assay}

Cells were incubated at $37^{\circ} \mathrm{C}$ for $48 \mathrm{~h}$ with the indicated concentrations of TSA. Viable cells were measured using the Cell Counting Kit-8 (Dojin, Kumamoto, Japan). All of the samples from each experiment were determined in the same assay.

\section{Cell death detection assay}

Cells were incubated at $37^{\circ} \mathrm{C}$ for $24 \mathrm{~h}$ with the indicated concentrations of TSA. DNA fragmentation was measured using the Cell Death Detection ELISA Kit (Roche, Penzberg, Germany) and each enrichment factor was calculated in accordance with the manufacturer's instructions.

\section{Cell cycle analysis}

AtT-20 cells were incubated for $24 \mathrm{~h}$ with medium alone (control) or medium containing $1 \mu \mathrm{M}$ TSA. The cells were then harvested by trypsinization, pelleted by centrifugation, and resuspended in Triton X-100. The cells were treated with $0.5 \%$ RNase A and stained with propidium iodine $(50 \mu \mathrm{g} / \mathrm{mL})$ at $37^{\circ} \mathrm{C}$ for $30 \mathrm{~min}$ and the cellular DNA content was analyzed using fluorescence-activated cell sorting (FACS). The cell cycle profiles were determined using BD FACSDiva ${ }^{\mathrm{TM}}$ soft- ware (Becton Dickinson, Franklin Lakes, NJ).

\section{RNA interference experiments}

PTTG1-specific and control small interfering (si) RNAs were designed and purchased from QIAGEN. Cells were transfected with siRNA using HiPerFect transfection reagent (QIAGEN) in accordance with the manufacturer's protocol. To determine PTTG1 mRNA levels, cells were seeded into 12 -well plates at a density of $12 \times 10^{4}$ cells/well and incubated in $1 \mathrm{~mL}$ of culture medium containing either control siRNA (siControl) or PTTG1-specific siRNA (siPTTG1; Mm_Pttg1_7) for $48 \mathrm{~h}$. The expression of PTTG1,POMC, and $B 2 M G$ mRNA was then examined using quantitative RT-PCR. The ACTH level in the medium was measured using an ACTH ELISA kit. To measure cell proliferation, cells were seeded in 96-well plates at a density of $1.5 \times$ $10^{4}$ cells/well and incubated for $24 \mathrm{~h}$ in $200 \mu \mathrm{L}$ of culture medium containing siControl or siPTTG1 prior to changing the media. Viable cells were measured $48 \mathrm{~h}$ after transfection using the Cell Counting Kit-8.

\section{Statistical analysis}

Each in vitro experiment was performed 3 times. Samples were run in triplicate for each group of experiments. Data are expressed as the mean \pm standard error of the mean. Statistical analysis was performed using analysis of variance (ANOVA) followed by Fisher's protected least-significant difference post hoc test or using the unpaired Student's $t$-test. The level of statistical significance was set at $P<0.05$.

\section{Results}

\section{Effect of TSA on POMC mRNA and ACTH levels}

AtT-20 cells were incubated with TSA to determine the time- and dose-dependent effects on POMC mRNA levels. A time course study indicated that $1 \mu \mathrm{M}$ TSA significantly decreased $P O M C$ mRNA levels. POMC mRNA levels fell to $37 \%$ of the control value (Fig. 1A) within $24 \mathrm{~h}$ of TSA addition. POMC mRNA levels were also decreased in a TSA dose-dependent manner (ANOVA; $P<0.0001$ ), with significant effects observed from $100 \mathrm{nM}$ to $1 \mu \mathrm{M}$ (Fig. 1B). Similarly, the ACTH level in the cell culture medium was also decreased in a dose-dependent manner (ANOVA; $P<$ 0.005 ), with significant effects observed from $100 \mathrm{nM}$ to $1 \mu \mathrm{M}$ TSA (Fig. 1C). To further examine a possible interaction between TSA and glucocorticoids, the 
effect of TSA and dexamethasone on POMC mRNA levels was examined. Both TSA and dexamethasone individually decreased $P O M C$ mRNA levels (Fig. 1D). However, the TSA-induced decrease in POMC mRNA levels were not modulated when TSA and dexamethasone were simultaneously added (Fig. 1D).

Effect of TSA on cellular proliferation and cell death

AtT-20 cells were incubated with TSA to determine the dose-dependent effects on cellular proliferation. Cellular proliferation decreased in a TSA dose-depen-
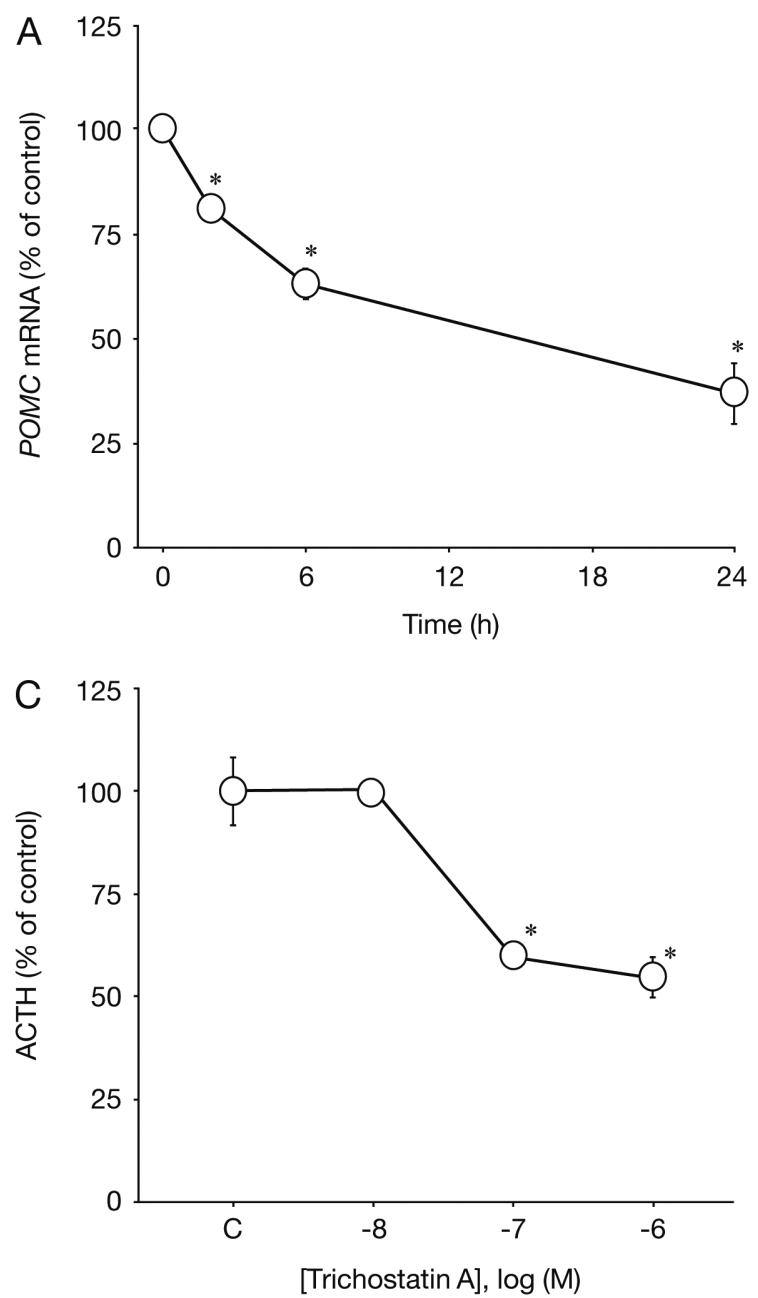

dent manner (ANOVA; $P<0.0001$ ), with significant effects observed from $100 \mathrm{nM}$ to $10 \mu \mathrm{M}$ TSA (Fig. 2A).

To examine whether TSA induced cell death, the level of cytoplasmic histone-associated DNA fragmentation was determined. DNA fragmentation increased in a TSA dose-dependent manner (ANOVA; $P<$ 0.0001 ), with significant effects observed from $100 \mathrm{nM}$ to $10 \mu \mathrm{M}$ TSA (Fig. 2B).

\section{Effect of TSA on the cell cycle profile}

Cell cycle distribution was assessed using flow
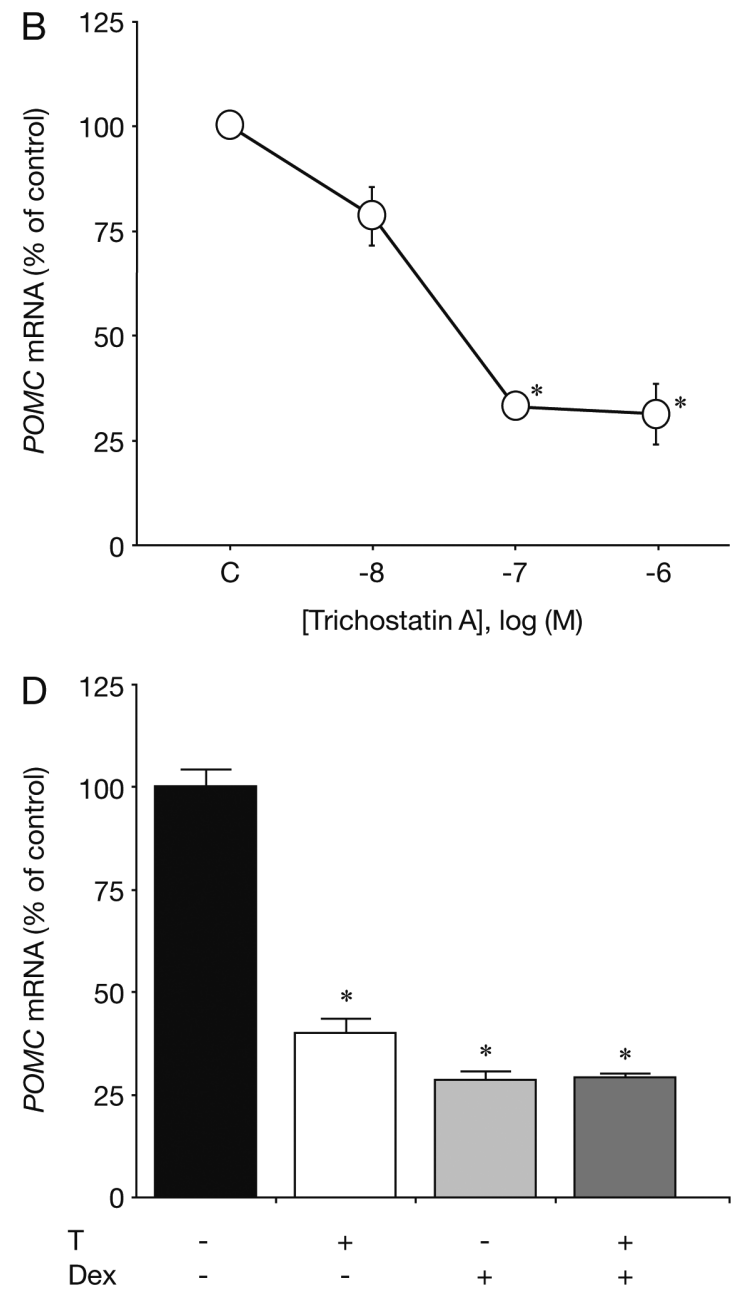

Fig. 1 Effect of TSA on proopiomelanocortin $(P O M C)$ mRNA and adrenocorticotropic hormone (ACTH) levels in AtT-20 cells. Cells were treated in triplicate and the average of 3 independent experiments is shown (the average of triplicates was considered as $\mathrm{n}=1$, in this experiment $\mathrm{n}=3$ ). Statistical analysis was performed using one-way analysis of variance (ANOVA) followed by Fisher's protected least-significant difference post hoc test. ${ }^{*} P<0.05$ (compared with control [C]). (A) Time-dependent effect of TSA on $P O M C$ mRNA levels: cells were incubated with medium containing $1 \mu \mathrm{M}$ TSA. (B) Dose-dependent effects of TSA on $P O M C$ mRNA levels: cells were incubated for $24 \mathrm{~h}$ with medium containing between $10 \mathrm{nM}$ and $1 \mu \mathrm{M}$ TSA. (C) Dosedependent effects of TSA on ACTH levels in AtT-20 cells: cells were incubated for $24 \mathrm{~h}$ with medium containing between $10 \mathrm{nM}$ and $1 \mu \mathrm{M}$ TSA. (D) Effect of TSA and dexamethasone on POMC mRNA levels: cells were incubated for $24 \mathrm{~h}$ with medium containing $1 \mu \mathrm{M}$ TSA (T) and/or $100 \mathrm{nM}$ dexamethasone (Dex). 
cytometry. FACS analyses indicated that the percentage of cells in G0/G1 phase was increased after incubation with $1 \mu \mathrm{M}$ TSA. Reciprocally, the percentage of cells in S phase decreased after incubation with $1 \mu \mathrm{M}$ TSA (Fig. 3).

\section{Effect of TSA on PTTG1 mRNA levels}

A time course study indicated that $1 \mu \mathrm{M}$ TSA potently decreased PTTG1 mRNA levels (ANOVA; $P<0.005$, Fig. 4A). Within $24 \mathrm{~h}$ of TSA addition, PTTG1 mRNA levels fell to $62 \%$ of the control value
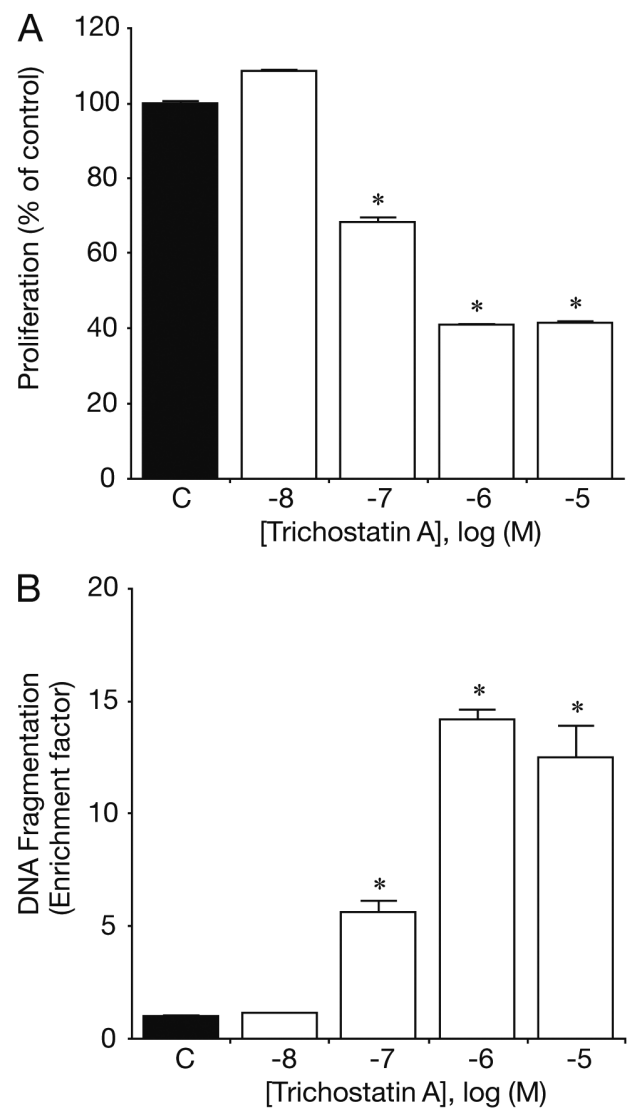

Fig. 2 Effect of TSA on cellular proliferation and cell death in AtT-20 cells. Cells were treated in triplicate and the average of 3 independent experiments is shown. Statistical analysis was performed using one-way ANOVA followed by Fisher's protected least-significant difference post hoc test. ${ }^{*} P<0.05$ (compared with control $[\mathrm{C}]$ ). (A) Effect of TSA on cellular proliferation in AtT-20 cells: cells were incubated for $48 \mathrm{~h}$ with medium containing between $10 \mathrm{nM}$ and $10 \mu \mathrm{M}$ TSA. Viable cells were measured using Cell Counting Kit-8. (B) Effect of TSA on cell death in AtT-20 cells: cells were incubated for $24 \mathrm{~h}$ with medium containing between $10 \mathrm{nM}$ and $10 \mu \mathrm{M}$ TSA. DNA fragmentation was measured using Cell Death Detection ELISA Kit.
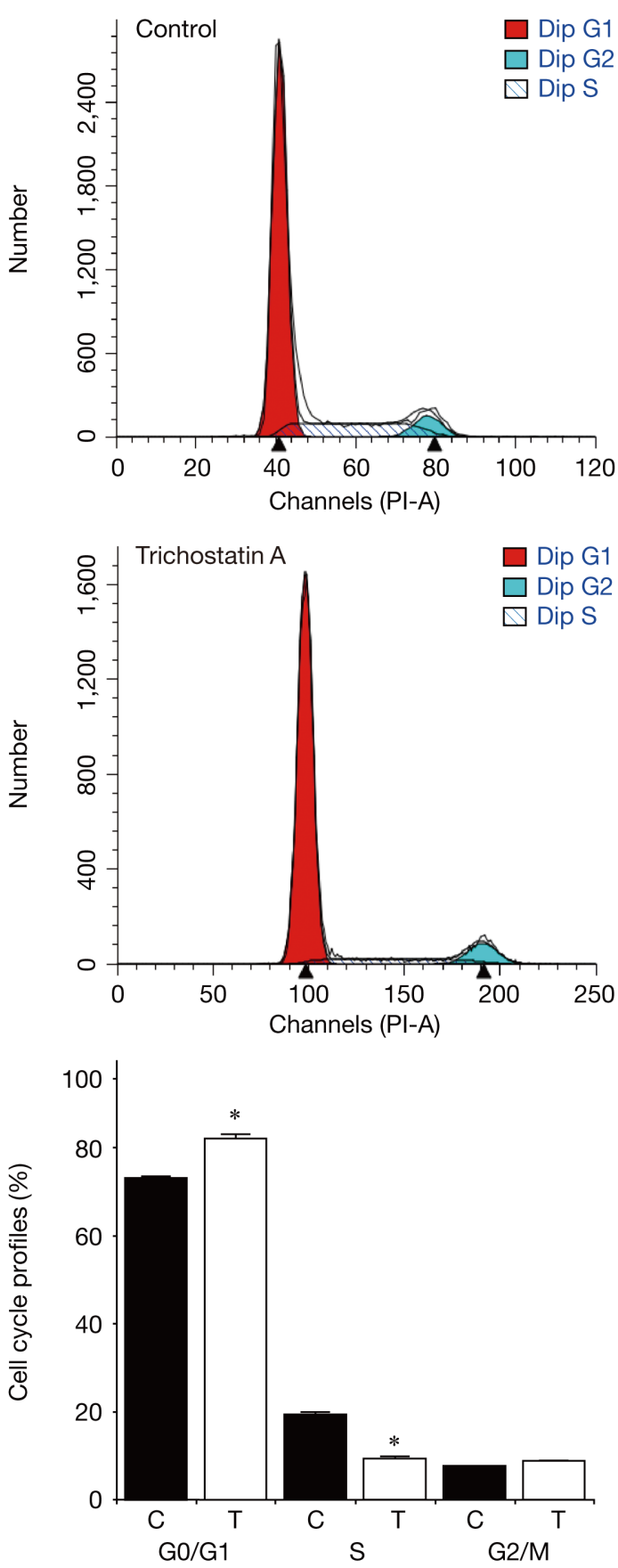

Fig. 3 Effect of TSA on the cell cycle profile of AtT-20 cells. Control cells were treated with medium and vehicle. A representative histogram is shown in the upper panels. Cells were treated in duplicate and the average of 3 independent experiments is shown in the lower panel. Statistical analysis was performed using one-way ANOVA followed by Fisher's protected least-significant difference post hoc test. ${ }^{*} P<0.05$ (compared with control $[\mathrm{C}]$ ). Cells were incubated for $24 \mathrm{~h}$ with $1 \mu \mathrm{M}$ TSA or vehicle containing DMSO. Cellular DNA content was analyzed using flow cytometry and the cell cycle profiles were determined using BD FACSDiva ${ }^{\mathrm{TM}}$ software. 
(Fig. 4A). PTTG1 mRNA levels also decreased in a dose-dependent manner (ANOVA; $P<0.0005$ ), with significant effects observed from $100 \mathrm{nM}$ to $10 \mu \mathrm{M}$ TSA (Fig. 4B). As a positive control, GADD45 $\beta$ levels were also measured in this experiment. TSA significantly increased GADD $45 \beta$ mRNA levels in timedependent and dose-dependent manners (ANOVA; $P<$ 0.001, Fig. 4C and 4D).

Effect of PTTG1 on cellular proliferation, POMC $m R N A$, and ACTH levels

We proceeded to examine the role of PTTG1 in AtT20 cells since PTTG1 could be involved in the regulation of cell proliferation. PTTG1 mRNA levels were
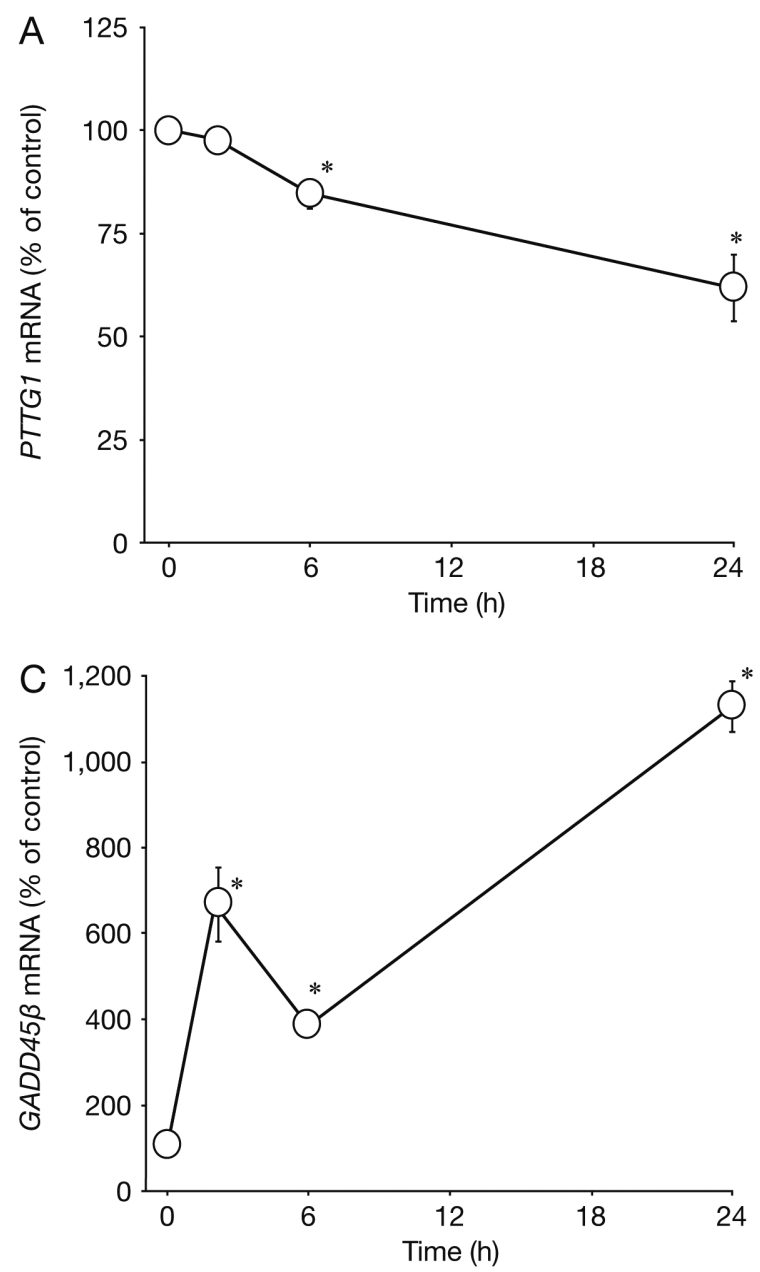

reduced by $42 \%$ in cells transfected with PTTG1specific siRNA $(P<0.01$; Fig. $5 \mathrm{~A})$ and $P T T G 1$ knockdown significantly inhibited cellular proliferation $(P$ $<0.005$; Fig. 5B). Its knockdown also significantly inhibited POMC mRNA and ACTH levels $(P<0.05$; Fig. 5C and 5D).

\section{Discussion}

In this study, we showed that the HDAC inhibitor TSA decreased POMC mRNA levels and the basal level of ACTH in the culture medium of AtT-20 cells. These results suggest that the HDAC inhibitor suppresses the autonomic synthesis and release of ACTH in cortico-
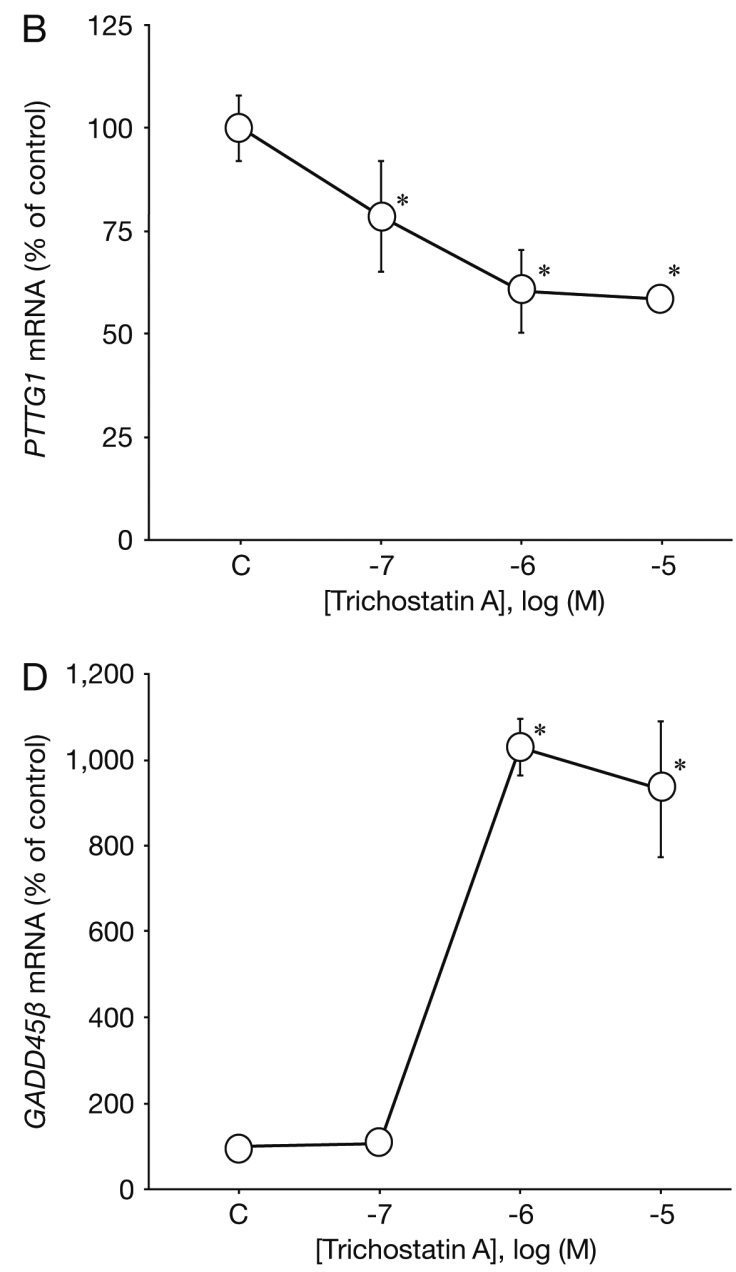

Fig. 4 Effect of TSA on pituitary tumor-transforming gene 1 (PTTG1) mRNA levels in AtT-20 cells. Cells were treated in triplicate and the average of 3 independent experiments is shown. Statistical analysis was performed using one-way ANOVA followed by Fisher's protected least-significant difference post hoc test. ${ }^{*} P<0.05$ (compared with control [C]). (A and C) Timedependent effect of TSA on PTTG1 and GADD $45 \beta$ mRNA levels: cells were incubated with medium containing $1 \mu \mathrm{M}$ TSA. (B and D) Dose-dependent effects of trichostatin A on PTTG1 and GADD45 $\beta$ mRNA levels: cells were incubated for $24 \mathrm{~h}$ with medium containing between $100 \mathrm{nM}$ and $10 \mu \mathrm{M}$ TSA. 

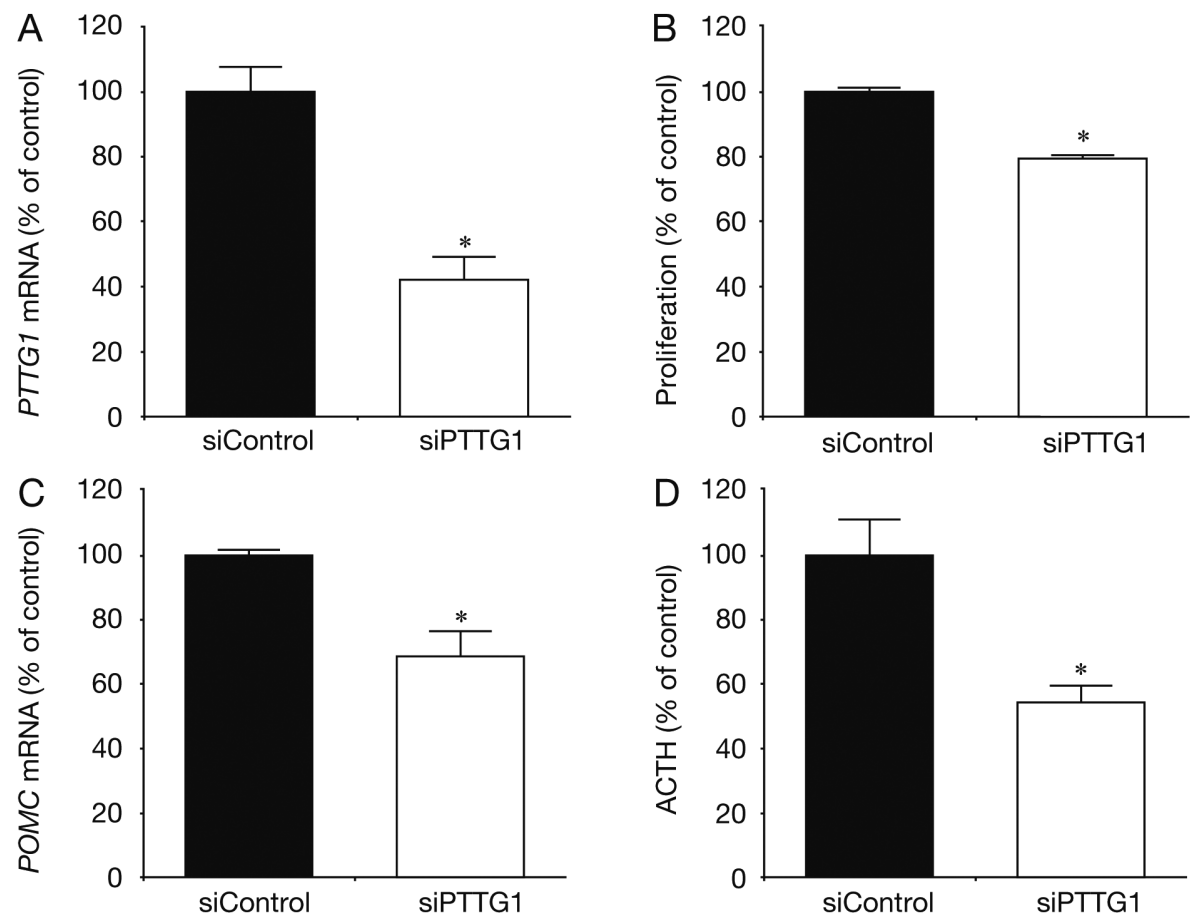

Fig. 5 Effect of PTTG1 on cellular proliferation, POMC mRNA, and ACTH levels in AtT-20 cells. Cells were treated in triplicate and the average of 3 independent experiments is shown. Statistical analysis was performed using the unpaired Student's $t$-test. ${ }^{*} P$ $<0.05$ (compared with control). (A, C, and D) Effect of PTTG1 on PTTG1 mRNA, POMC mRNA, and ACTH levels: cells, seeded into 12 -well plates at a density of $12 \times 10^{4}$ cells/well, were incubated for $48 \mathrm{~h}$ in $1 \mathrm{~mL}$ of culture medium containing control or PTTG1-specific small interfering (si) RNA (siControl and siPTTG1, respectively). (B) Effect of PTTG1 on cellular proliferation: cells, seeded into 96-well plates at a density of $1.5 \times 10^{4}$ cells/well, were incubated for $48 \mathrm{~h}$ in $200 \mu \mathrm{L}$ of culture medium containing control or PTTG1-specific small interfering (si)RNA (siControl and siPTTG1, respectively).

troph tumor cells. We also showed that TSA decreased AtT-20 cell proliferation. In accordance with this finding, TSA was found to increase DNA fragmentation in AtT-20 cells, suggesting that it induces cell death in corticotroph tumor cells. FACS analyses indicated that TSA increased the percentage of AtT-20 cells in G0/G1 phase, suggesting that the drug may attenuate cell cycle progression or cause cell cycle arrest in G0/G1 phase. This would also result in the inhibition of cellular proliferation. Decreased cell numbers in TSA cultures could contribute to the observed decrease in ACTH levels.

Valproic acid, an HDAC2 inhibitor, has been reported to prevent the suppression of $P O M C$ promoter activity by glucocorticoid in AtT-20 cells [17]. In our study, TSA, an HDAC1 and 2 inhibitor, treatment resulted in decreased levels of $P O M C$ mNA. The effect was not modulated by glucocorticoid treatment of the AtT-20 cells. It is not clear whether this discrepancy is a result of differences between $P O M C$ promoter activity and mRNA levels. HDAC2 mRNA levels have been reported to be decreased in corticotroph tumors
[18], but no such data exist for the expression of other HDAC subtypes. It is possible that valproic acid and TSA exhibit different specificities for the HDAC subtypes, and this could account for the observed results. Even in the presence of glucocorticoids, TSA appeared to decrease ACTH production.

Previous studies have shown that HDAC inhibitors repress PTTG1 mRNA levels in a manner similar to Hsp90 inhibitors [11]. In the present study, we found that TSA gradually decreased PTTG1 mRNA levels in AtT-20 cells, similar to the Hsp90 inhibitors 17-AAG and CCT018159 [12]. PTTG1 has been shown to facilitate cell cycle progression and increase pituitary cell proliferation [9], and that the overexpression of PTTG1 results in the proliferation of pituitary gonadotroph cells [8]. These findings suggest that PTTG1 may be involved in the HDAC inhibitor-induced suppression of cellular proliferation in AtT-20 cells. Indeed, in the present study, PTTG1 knockdown inhibited cellular proliferation. Its knockdown also inhibited POMC mRNA and ACTH levels. Taken together, these find- 
ings indicate that PTTG1 may be responsible, at least in part, for the TSA-induced suppression of cellular proliferation, and ACTH synthesis and secretion in AtT-20 cells.

\section{Conclusion}

TSA decreased POMC mRNA and ACTH levels in AtT-20 cells. The drug also decreased PTTG1 mRNA levels and cellular proliferation, presumably due to the induction of cell cycle arrest and cell death. PTTG1 knockdown inhibited cellular proliferation. Thus, TSA may inhibit cellular proliferation, as well as ACTH synthesis and secretion, via decreased PTTG1 expres- sion in AtT-20 cells.

\section{Acknowledgments}

We wish to thank the Department of Social Medicine, Hirosaki University Graduate School of Medicine, for assistance with FACS analysis. This research did not receive any specific grants from any funding agencies in the public, commercial, or not-for-profit sector.

\section{Conflicts of Interest}

None of the authors have any potential conflicts of interest associated with this research.

\section{References}

1. Nieman LK, Biller BM, Findling JW, Newell-Price J, Savage MO, et al. (2008) The diagnosis of Cushing's syndrome: an Endocrine Society Clinical Practice Guideline. J Clin Endocrinol Metab 93: 1526-1540.

2. Kageyama K, Oki T, Sakihara S, Nigawara T, Terui K, et al. (2013) Evaluation of the diagnostic criteria for Cushing's disease in Japan. Endocr J 60: 127-135.

3. Biller BM, Grossman AB, Stewart PM, Melmed S, Bertagna X, et al. (2008) Treatment of adrenocorticotropin-dependent Cushing's syndrome; a consensus statement. J Clin Endocrinol Metab 93: 2454-3462.

4. Rhode PR, Gorski J (1991) Growth and cell cycle regulation of mRNA levels in GH3 cells. Mol Cell Endocrinol 82: 11-22.

5. Kageyama K, Sugiyama A, Murasawa S, Asari Y, Niioka K, et al. (2015) Aphidicolin inhibits cell proliferation via the p53-GADD $45 \beta$ pathway in AtT-20 cells. Endocr J 62: 645-654.

6. Pei L, Melmed S (1997) Isolation and characterization of a pituitary tumor-transforming gene (PTTG). Mol Endocrinol 11: 433-441.

7. Zhang X, Horwitz GA, Heaney AP, Nakashima M, Prezant TR, et al. (1999) Pituitary tumor transforming gene (PTTG) expression in pituitary adenomas. J Clin Endocrinol Metab 84: 761-767.

8. Chesnokova V, Zonis S, Zhou C, Ben-Shlomo A, Wawrowsky K, et al. (2011) Lineage-specific restraint of pituitary gonadotroph cell adenoma growth. PLoS One 6: e17924.

9. Chesnokova V, Zonis S, Wawrowsky K, Tani Y, BenShlomo A, et al. (2012) Clusterin and FOXL2 act concordantly to regulate pituitary gonadotroph adenoma growth. Mol Endocrinol 26: 2092-2103.

10. Hernández A, López-Lluch G, Bernal JA, Navas P, Pintor-Toro JA (2008) Dicoumarol down-regulates human PTTG1/Securin mRNA expression through inhibition of Hsp90. Mol Cancer Ther 7: 474-482.

11. Hernández A, López-Lluch G, Navas P, Pintor-Toro JA (2009) HDAC and Hsp90 inhibitors down-regulate PTTG1/securin but do not induce aneuploidy. Genes Chromosomes Cancer 48: 194-201.

12. Sugiyama A, Kageyama K, Murasawa S, Ishigame N, Niioka K, et al. (2015) Inhibition of heat shock protein 90 decreases ACTH production and cell proliferation in AtT-20 cells. Pituitary 18: 542-553.

13. Riebold M, Kozany C, Freiburger L, Sattler M, Buchfelder M, et al. (2015) A C-terminal HSP90 inhibitor restores glucocorticoid sensitivity and relieves a mouse allograft model of Cushing disease. Nat Med 21: 276-280.

14. Wang DF, Helquist P, Wiech NL, Wiest O (2005) Toward selective histone deacetylase inhibitor design: homology modeling, docking studies, and molecular dynamics simulations of human class I histone deacetylases. J Med Chem 48: 6936-6947.

15. Kageyama K, Hanada K, Suda T (2009) Differential regulation of urocortins 1-3 mRNA in human umbilical vein endothelial cells. Regul Pept 155: 131-138.

16. Kageyama K, Hanada K, Suda T (2010) Differential regulation and roles of urocortins in human adrenal H295R cells. Regul Pept 162: 18-25.

17. Bilodeau S, Vallette-Kasic S, Gauthier Y, FigarellaBranger D, Brue T, et al. (2006) Role of Brg1 and HDAC2 in GR trans-repression of the pituitary POMC gene and misexpression in Cushing disease. Genes Dev 20: 2871-2786.

18. Tateno T, Izumiyama H, Doi M, Yoshimoto T, Shichiri M, et al. (2007) Differential gene expression in ACTHsecreting and non-functioning pituitary tumors. Eur $J$ Endocrinol 157: 717-724. 